following concentrations, the total mitotic counts observed expressed as a percentage of mitosis in the controls were as follows :

(a) $2.5 \times 10^{-6} M, 82 \cdot 0 \pm 4.5$ per cent.

(b) $3 \times 10^{-6} M, 69 \cdot 3 \pm 2 \cdot 3$ per cent.

(c) $4 \times 10^{-6} M, 51 \cdot 6 \pm 1.0$ per cent.

(d) $5 \times 10^{-6} \mathrm{M}, 22.7 \pm 4.9$ per cent.

(e) $6 \times 10^{-6} M, 23 \cdot 7 \pm 4 \cdot 1$ per cent.

For $3 \times 10^{-6} M$ initial concentration, the mitotic count varied with the time of application, having the value after 18 hours, $61 \cdot 7 \pm 4 \cdot 7$ per cent; after 24 hours, $69 \cdot 3 \pm 2 \cdot 3$ per cent; after 36 hours, $75 \cdot 2 \pm 2.9$ per cent; and after 48 hours, $82.5 \pm$ $3 \cdot 4$ per cent. The values for 24 and 36 hour. are the most reliable.

In each of the experiments showing the effects of $X$-radiation on the cells treated with the synthetic vitamin $K$ substitute, four sets of cultures were chosen. To two, the compound was added to give a final concentration of $3 \times 10^{-6} M$; the other two were used as controls for the compound only and for the radiation only. One group treated with synthetic vitamin $K$ substitute and one control group were irradiated after 18 hours with $244 \mathrm{r}$. of X-radiation of effective wave-length approximately $0.20 \mathrm{~A}$. (H.V.L. $0.5 \mathrm{~mm}$. copper) delivered in 2 minutes. Mitotic counts were made for all four groups at 24, 36 and 48 hours. The results are summarized in Fig. 1, and indicate significant potentiation of the mitotic-inhibiting effects of X-radiation and of the synthetic vitamin $\mathrm{K}$ substitute. For example, after 24 hours, X-radiation alone produced $64.9 \pm 1.6$ per cent of the number of mitoses present in the controls, and synthetic vitamin $\mathrm{K}$ substitute alone $69 \cdot 3 \pm$ $2 \cdot 3$ per cent. The observed effects of the combination produced $14 \cdot 0 \pm 3.8$ per cent, while independent action would give $45 \cdot 0 \pm 1.9$ per cent. A similar highly significant difference was found at 36 hours; and even at 48 hours, where the experiment is becoming difficult, a significant effect was found.

With regard to the preliminary clinical trials, the qualitative findings so far are not inconsistent with the above measurements. The low toxicity of the synthetic vitamin $\mathrm{K}$ substitute has been confirmed. In twenty-five patients with advanced cancer, no attributable toxic effects were observed with doses of $100 \mathrm{mgm}$. administered intramuscularly daily for times up to six weeks. One man received $500 \mathrm{mgm}$. intramuscularly daily for 42 days without any demonstrable toxic effect. X-ray therapy was commenced at least three days after the synthetic vitamin $\mathrm{K}$ substitute.

The histological changes found in biopsy specimens are exemplified in Fig. 2, which shows typical fields, for a case of advanced squamous cell carcinoma of the floor of the mouth: $(a)$ in the control biopsy specimen; $(b)$ in that taken after administration of $100 \mathrm{mgm}$. of synthetic vitamin $K$ substitute daily for 16 days; and $(c)$ that taken at 4 days after the end of a course of X-ray therapy in which the minimum tumour dose $3,500 \mathrm{r}$. was delivered in overall time 8 days, by which time the synthetic vitamin $\mathrm{K}$ substitute had been given for 44 days. In the control specimen (a) 5,000 cells were counted, and the frequency of mitosis was $3.98 \pm 0.28$ per cent. In $(b)$, after synthetic vitamin $K$ substitute alone, the frequency of mitosis was found by counting 10,000 cells to be $1 \cdot 12 \pm 0 \cdot 11$ per cent, indicating a highly significant reduction. Further, the ratio of prophases to metaphases was significantly reduced.
After the irradiation, counts were impossible because all the tumour cells were grossly degenerate. At the doses used, the synthetic vitamin $K$ substitute alone produced many mitotic abnormalities, including clumping and stickiness of chromosomes and anaphase bridges.

Summarizing: a synthetic vitamin $\mathbf{K}$ substitute, tetrasodium 2 - methyl - I : 4 naphthohydroquinone diphosphate, produces mitotic inhibition in chick fibroblast cultures and in some human carcinomata. In the tissue cultures, significant potentiation of the effects of X-radiation and of the synthetic vitamin $K$ substitute in inhibiting mitosis is found under suitable conditions. Preliminary clinical trials confirm the low toxicity of the synthetic vitamin $K$ substitute. At the present stage of investigation, no therapeutic value is claimed.

${ }^{1}$ Mitchell, J. S., Brit. J. Exp. Path., 23, 285, 296, 309 (1942); Brit. J. Radiol., 16, 339 (1943); Annual' Rep. Brit. Empire Cancer Campaign, 62 (1944); Schweiz. med. Wschr., 76, 883 1946).

v. Euler, H., and Hevesy, G., Kgl. Danske Vidensk. Selskab. Biol. Medd., 17, 8 (1942); K. Svenska Vetenskapsakad. Arkiv Kemi,

17 A, Nr.' 30 (1944).
Ahlstrom, L., v. Euler, H., and Hevesy. G., K. Svenska Vetenskapsakad. Arkiv Kemi, 19 A', Nr. 9 (1944).

akad. Arkiv Kemi, 19 A, Nr. 9 (1944).

Stowell, R., Rex. Cancer Res., 5, 169 (1945).

${ }^{2}$ Lehmann, F. E., Verhandl. Ver. Schweiz. Physiol. (June 1942).

s Lehmann, F. E., Lüscher, M., and Huber, W., Rev. Suisse Zool., $52,342,349,354$ (1945)

- Goodman, I., and Gilman, A., "Pharmacological Basis of Therapeutics" (New York, 1941), 1295.

Fromberg, K., Z. Vitaminforsch. 11, 65 (1941) (see Morton, R. A., "Annual Rev. Biochem." (1942), 385).

\section{PLASTIC OPTICAL SYSTEMS FOR TELEVISION}

IN the type of television receiver most commonly 1 used at the present time, the picture is produced on the fluorescent screen of the cathode ray tube, which is viewed directly or through a suitably placed plane mirror. The 9- or 12-in. cathode ray tubes normally used give pictures of about 8 in. by 6 in. in dimensions, while a somewhat larger picture is obtained with a 15-in. tube. This, however, probably represents the practical limit of picture size in this type of domestic receiver, since larger cathode ray tubes are unwieldy and expensive items. At the same time, it is desirable that the television receiver of the future should produce a picture of about twice the above size in linear dimensions, and preferably on a flat screen. With this object in view, developments had begun several years ago of a reproducing system using a small cathode ray tube with a fluorescent screen only two or three inches in diameter, on which a bright clear image is produced, the light from this image being then projected through a suitable optical system to give an enlarged picture on a flat screen. While considerable progress has been made in cathode ray tube design, the picture brightness obtainable on the tube is insufficient to give satisfactory results when using an optical system of the conventional type. For this reason the Schmidt optical system, which was originally designed for use in astronomical telescopes, has been applied to the projection of television pictures. The great advantage of this system is that it has a large lightgathering property, and so enables the utmost use to be made of the picture-brightness on the cathode ray tube.

As mounted for use in a television receiver, a deep concave mirror of large aperture is placed opposite 
the end of the cathode ray tube and projects the light forward past the tube towards the viewing screen. In order to correct for the spherical aberration introduced by a mirror of such large aperture, a corrector plate is introduced into the projection system. This plate has a non-spherical surface of complex shape and, in the Schmidt system, is mounted at the centre of curvature of the mirror. To produce such an optical system in glass is, however, a slow and expensive matter, since the aspherical surfaces of the corrector plate require long and patient hand-work by a highly skilled craftsman. Although many attempts have been made to produce such plates by means of machines designed to work the surfaces automatically, this has so far not been considered to be an economic proposition for the mass-production of domestic television receivers. These limitations have now been largely removed by recent developments in the formation and use of transparent plastic materials, and particularly by the introduction of a surface-finishing process by means of which plastic components of high optical quality can be produced on a large manufacturing scale.

A description of these developments with demonstrations of their application to television reception was given in a lecture on May 29 before the Television Society by Dr. D. Starkie, of the Plastics Division of Imperial Chemical Industries, Ltd. Two plastic materials are available in bulk supply in Great Britain. They are poly-methyl-methacrylate and poly-styrene, and are supplied in optically pure forms as 'Transpex 1' and 'Transpex 2 respectively, with transmission values for visible light corresponding approximately to those of crown and flint glass. These materials are sensibly unaffected by continuous exposure to sunlight, and, although they have a softening temperature of about $120^{\circ} \mathrm{C}$., by taking great care to avoid any strain in the material during fabrication, finished components show no measurable change in form when used under the most severe operating conditions. The production of the components takes place in two stages. First, a 'preform' is cast as accurately as possible by some known method. Then a thin skin of the same material is built up on the surface of this preform inside an optically worked glass mould, until the surface of the component makes optical contact at all points with the mould. A transparent mould material is necessary since part of the reproduction process is polymerization by light; but, in addition, glass is the hardest material available in bulk supply and all risk of scratching during use must be avoided. The aspheric moulds are first machined as accurately as possible and then finished by a skilled optical worker by hand. The preparation of such moulds is still a long and expensive matter; and it is only justified by the fact that, once a mould is made, a considerable number of accurate plastic reproductions can be made from it. The time required to make an optical component by the surface-finishing process is quite long, although the actual handling time by the operators is short. It has been decided, therefore, that in order to keep production costs low enough to allow the optical systems to be used in domestic television receivers, a large number of moulds should be used and these should travel through the various stages of the process on a mechanical conveyor. A factory to be operated along these lines is being prepared, and it is hoped to start manufacture at the end of this year.
Dr. Starkie demonstrated two prototype Schmidt television projection systems for home receivers, using cathode ray tubes of $2 \frac{1}{4}$ or $3 \frac{1}{2} \mathrm{in}$. diameter, respectively. The picture size given by both systems is 16 in. $\times 13$ in., the chromatic aberration is small, and the resolution is claimed to be far better than is required for the present B.B.C. television transmissions using 405-line scanning. Although the smaller of the two systems requires a 'throw distancê' of $40 \mathrm{in}$. between the cathode ray tube and the viewing screen, it was shown how this could conveniently be incorporated in a receiver console of normal dimensions. A third Schmidt system suitable for television projection in small cinemas was also demonstrated: this contained a mirror of 18 in. diameter and gave a picture with a length of diagonal of $12 \frac{1}{2} \mathrm{ft}$.

Although the lecture was primarily devoted to the use of plastic optical components in television reception, it was pointed out that since the new surface-finishing process allows complicated aspherical optical components to be made at a reasonable cost it is likely to have an important effect in the general field of applied optics.

\section{BRITISH IRON AND STEEL RESEARCH ASSOCIATION OPENING OF SKETTY HALL LABORATORIES}

$\mathrm{S}^{\mathrm{K}}$ ETTY HALL, Swansea, was opened on July 3 as the South Wales Laboratories of the British Iron and Steel Research Association. Mr. G. H. Latham, president of the British Iron and Steel Research Association, received a gold key from the Mayor of Swansea, and guests proceeded to an inspection of the Laboratories.

At present the bulk of the Association's work is of necessity carried out through the facilities of its members and at the universities and other appropriate institutions. Nevertheless, considerable progress has been made in establishing a number of laboratories specially adapted for co-operative research. For example, at the University of Sheffield a team is studying problems connected with rolling practice, and plans are well advanced for the establishment of a metal flow station in Sheffield for practical investigations into all forms of metal working and plastic de. formation problems ; in London, a physics laboratory is shortly to be opened ; there is a corrosion-testing laboratory at Birmingham, and marine biological work is carried out at Millport, Scotland.

At Sketty Hall, a mansion with an interesting local history extending over a century and a half, made available to the Association by the Swansea Corpora: tion, comprehensive facilities have been provided.

The chemistry section has a spacious laboratory, and the metallurgical section has two laboratories, all on the ground-floor. The metallurgical rooms ar respectively equipped with various heat-treatment furnaces and physical testing apparatus. On the same floor is the small workshop with the instrument mechanic's room adjacent, and the galvanizing and tinning shop, which will be sited in what seems to have formerly been a brew house. This shop is already furnished with ventilation for drawing off the brewery fumes, though the arrangements may have to be improved to dispose of the rather less appetizing byproducts of the shop's new functions. 